\title{
Task Design of Task-Based Language Teaching in College English - A Case Study on Criticism: Don't Take It Personally
}

\author{
Yuxia Huang* \\ School of Foreign Languages, Leshan Normal University, Leshan 614000, Sichuan Province, China \\ *Corresponding author: Yuxia Huang, 244544082@qq.com
}

Copyright: ( $) 2022$ Author(s). This is an open-access article distributed under the terms of the Creative Commons Attribution License (CC BY 4.0), permitting distribution and reproduction in any medium, provided the original work is cited.

\begin{abstract}
Task-based language teaching (TBLT) is a new English teaching method, in which teachers design specific tasks before classes, and students then acquire knowledge as well as develop their communicative competence and English proficiency by completing these tasks in class. In the whole process, the most important thing is task design in that it will directly affect the implementation and effect of TBLT if the teacher is unable to handle the task design properly. This paper aims to discuss on how to design better tasks to achieve the objective of helping students develop their communicative competence by taking Text A (Criticism: Don't Take It Personally) of Unit 7 (Interpersonal Relationships) in the $21^{\text {st }}$ Century Practical College English (Book 2) as an example under the concept of TBLT.
\end{abstract}

Keywords: College English; TBLT; Task design; Communicative competence

Online publication: January 20, 2022

\section{Introduction}

During the traditional period, grammar-translation method was used. It is an explicit and conscious learning process, mainly applied to reading and translation. However, it is mainly for advanced and intermediate learners. Later on, during the reform period, direct method was used, which was found suitable for teaching some visual nouns and verbs, but not the abstract ones. However, students were unable to learn grammar systematically and they tended to be confused with what the teacher showed or drew. Then, during the innovative period, audio-lingual method or situational method was used, which focused on the imitation of the teacher but neglected the teaching of vocabulary. There was no explicit grammar instruction, and much attention was paid to correct pronunciation. Finally, in the modern period, communicative method is used. Richards and Rodgers pointed out that there are three principles in communicative language teaching (CLT): communication principle, task principle, and meaningfulness principle ${ }^{[1]}$.

In the late 1980s to early 1990s, CLT was not so popular, but the essence remained: the ideas of tasks. According to Wang Qiang ${ }^{[2]}$, TBLT developed from CLT. It emphasizes both form and communication in the process of teaching. Thereafter, several books on using tasks in language teaching appeared, including Second Language Pedagogy [3], Candling's and Murphy's co-edited collection of essays ${ }^{[4]}$, Designing Tasks for Communicative Classroom ${ }^{[5]}$, and so on. With the publication of A Framework for Task-based Learning ${ }^{[6]}$, TBLT has started from theory to practice.

In order to know how to design tasks and the existing problems in TBLT, this paper will deal with how to design better tasks to develop students' English competence and improve the teaching effect. 


\section{Theory of TBLT and task}

\subsection{Definition of TBLT}

According to Brown ${ }^{[7]}$, TBLT aims to put tasks as the center of metrological focus. In TBLT, students can improve their language competence and self-confidence through completing meaningful tasks, including inquiring about directions, taking a trip, shopping, etc. In this process, students will be evaluated not by the accuracy of language, but by the completion of a task.

\subsection{Basic model of TBLT}

Willis divided the teaching process into three phases: pre-task, task cycle, and language focus ${ }^{[6]}$.

In the pre-task phase, teachers should first introduce the topic and related tasks and then help the students to familiarize with the topic. Besides, teachers should bring in related words, phrases, and sentence structures to stimulate students' prior knowledge, thus strengthening their confidence to finish the task.

In the task-cycle phase, there are three parts: implementing task, planning, and report. In this phase, students have full opportunity to express their ideas. All the tasks can be completed through cooperation in groups. Moreover, more attention will be on the accuracy of language expression in order to report to the whole class. At the end, they will share their outcomes with the class, and a conclusion will be made by the teacher.

The language focus phase includes language analysis and practice. In this phase, teachers would help students systematically summarize the observed linguistic features based on completing several tasks. If necessary, they would learn and practice the language consciously. This is an important conclusion in the teaching process.

In TBLT, the core content is to communicate with others. Students are encouraged to speak first, then identify the meaning, and finally, learn and practice the important language aspects. In that way, it can develop students' skills of applying language into real life.

\subsection{Definition of "task"}

Willis pointed out that tasks are activities where language learners can realize their goals by communicating with others ${ }^{[6]}$. Generally speaking, a task involves authentic language use, in which learners focus on meaning rather than on form. It requires much engagement from learners and has a clear objective as well as strong communicative purpose. It is goal-oriented, and the outcome can only be reached by interaction between participants.

\subsection{Principles of task design}

There are five principles of task design: authenticity principle, staged principle, student-centered principle, learning-by-doing principle, goal-oriented and outcome principle.

The first is authenticity principle. The task needs to be authentic, including the language input, their understanding, and social contexts. Therefore, teachers should provide the students with explicit and authentic information when designing tasks.

The second is staged principle. All tasks in a text should form a stage; that is, tasks should be designed from easy to difficult or in the form of a task chain composed of several sub-tasks.

The third is student-centered principle. Teachers should think about students' needs, interests, experiences, and abilities. The tasks should be in such a way that students can master the language and apply it into real life by completing these tasks. Students are encouraged to solve problems on their own by discussing with their partners. 
The fourth is learning-by-doing principle. Students can master a certain language by completing tasks, such as drawing a picture, making notes, reading to a story, and so on. It can motivate their learning interest and provide an enjoying experience of successfully fulfilling those tasks. The students should interact with others and exchange relevant information while carrying out these activities.

The last one is goal-oriented and outcome principle. In the process of fulfilling tasks, students must have an aim to achieve, and then communicate with others. There must be an outcome, including evident ones and non-evident ones, such as a picture, a written plan, a list, or a decision.

\section{Task design of TBLT for Criticism: Don't Take It Personally}

Upon understanding the theory of TBLT and task as well as the principles of designing tasks, this section discusses the task design for the text Criticism: Don't Take It Personally.

\subsection{Task design and the design intent in the pre-reading phase}

In the pre-reading phase, three tasks are designed.

(1) Task 1: Review, which involves going over the useful expression about criticism.

(2) Task 2: Lead-in activity, which involves watching a short video clip about criticism and then thinking about three questions: "What does the video talk about?"; "Who is criticized and why?"; "How does he respond to it?".

(3) Task 3: Discussion with partners about three questions: "What is criticism?"; "What is the function of criticism?", "How will we handle it when we are criticized?".

Why are these three tasks designed? First of all, the text is about the right attitude toward criticism. In the first task, the text can be easily understood by reviewing useful expressions, which can be used in roleplaying later. The second and third tasks can stimulate students' learning interest. Students can learn about the theme of the text and understand the definition as well as the function of criticism. All in all, the three tasks embody the authenticity principle and the staged principle.

\subsection{Task design and the design intent in the while-reading phase}

In the while-reading phase, four tasks are designed.

(1) Task 1: Text structure and main idea of each part; scanning through the entire text and filling in the blanks with the information obtained from reading.

\begin{tabular}{ll}
\hline Topic of the text & Don’t take criticism personally \\
Part 1 (Paragraphs 1-2) & Criticism comes from various sources, and criticism stings. \\
Part 2 (Paragraphs 3-11) & How to handle it when we are criticized. \\
Part 3 (Paragraphs 12-13) & It is important to accept criticism as a part of life. \\
\hline
\end{tabular}

(2) Task 2: Major points of Part 1; scanning part 1 and filling in the blanks.

(a) Criticism can come from your parents, your employer, your friends, or your teachers.

(b) Criticism may make us feel hurt, angry, and become defensive. 
(3) Task 3: Major points of Part 2; scanning Part 2 and filling in the blanks.

Paragraph 3: Any sort of criticism is to teach you something, so we should take criticism as a learning tool.

Paragraphs 4-7: In order to learn from criticism, it is essential to determine whether the criticism is valid.

Paragraphs 8-11: Criticism can be vague or general, so we should ask for details.

As Part 2 is the main part of this text, with three sub-titles ("A Learning Tool," "A Valid Question," and "Details! Details! Details!"), it is essential for to divide this part into three sub-tasks.

(a) Sub-task 1: Role-playing in Paragraph 3 ("A Learning Tool”).

The students will be divided into three groups, and each group will be required to perform a scene: "a teacher criticizing a student," "a parent criticizing a child," and "an employer criticizing an employee." Subsequently, each group will be required to select a group of volunteers to act it out. The other students will then watch their performance and discuss the question: "What can we learn from each criticism?". Finally, the students will be required to summarize and fill in the blanks.

\begin{tabular}{lll}
\hline Criticizer & Criticism & Purpose \\
\hline Teacher & Your English essay has some faults. & Helping you to express yourself. \\
Parent & Your bedroom is untidy. & Teaching you to be more organized. \\
Employer & You have misfiled some documents. & Hoping that you to find the documents with relative ease when \\
& & necessary. \\
\hline
\end{tabular}

(b) Sub-task 2: Role-playing in Paragraphs 4-7 (“A Valid Question”).

The students will be required to create a dialogue about criticism and personal opinion, and then several students will be selected to act it out. The other students will watch their performance and then judge whether the criticism is a valid one or a personal one. Finally, the students will be required to summarize and fill in the blanks.

\begin{tabular}{lll}
\hline Criticizer & Criticism & A valid criticism or a personal opinion \\
\hline Mother & You look better with short hair. & A personal opinion \\
Employer & You made a mistake at your after-school job. & A valid criticism \\
\hline
\end{tabular}

(c) Sub-task 3: Role-playing in Paragraphs 8-11 (“Details! Details! Details!”).

The students will be required to prepare a dialogue that includes criticism, inquiring for details in person, as well as a solution. Then, on the basis of volunteering, two groups of students will be asked to act it out, and the others would watch their performance carefully. Thereafter, the students will answer a question: "When we are criticized, what should we do when we do not know how to correct it?". Finally, the students will be required to summarize and fill in the blanks.

\begin{tabular}{lll}
\hline Criticizer & Criticism & Vague or detailed \\
\hline Your Boss & Your report just doesn't cut it. & Vague \\
\hline
\end{tabular}

Then the students will answer the following questions: "Is it too wordy?", "Are there enough details?", "Does it need more statistics?", "Is it lacking in content or conclusion?". 
(4) Task 4: Major points of Part 3; scanning Part 2 and filling in the blanks.

(i) If you constantly worry that you might be criticized, you will not get anything done.

(ii) If you do not learn to respond to criticism positively, it would deflate your ego and lower your self-esteem.

Thereafter, a video clip, showing the most famous celebrities in Hollywood getting criticized by their fans, will be played. After watching, students will be required to think about this question: "How should we respond to criticism?".

There are several reasons for the design of the four tasks in the while-reading phase. Firstly, in Task 1, by scanning through the entire text, especially the sub-titles, it enables students to understand the structure of the text and the main idea of each part, which is a vital reading skill that students need to master.

Secondly, in Task 2, students would be able to obtain detailed information about Part 1 and understand the sources as well as effects of criticism through filling in the blanks.

Thirdly, in Task 3, students would be able to understand the main idea of Part 2. Above all, it is necessary to divide Part 2 into 3 sub-parts according to the sub-titles because Part 2 is the main body of the text.

In Sub-task 1, there are three forms of criticisms in this paragraph; thus, it is a good idea to act out all the three scenes. The students are divided into three groups in order to encourage them, and each group will then present a scene. In addition, by discussing the performances and answering the question, this activity would improve students' speaking skills. This activity can also deepen students' understanding of the paragraph by summarizing: "All criticisms have one purpose - to teach you something."

In Sub-task 2, the main idea of this subpart is to distinguish a valid criticism from a personal opinion, so it is necessary to ask students to come up with some dialogues about criticisms and personal opinions. Sub-task 2 trains students' critical thinking and improves their holistic knowledge about language learning, including theme, structure, grammar, and language points. Besides, students will be able to understand this part better by filling in the blanks as such: "We must distinguish a valid criticism from a personal opinion as a valid criticism can actually help us succeed."

In Sub-task 3, the main idea of this part is not knowing what the problem is when being criticized. In that case, one should ask for details in person to help rectify the problem. In this sub-task, students are asked to prepare a dialogue that includes criticism as well as the detailed solution. In that way, it helps to improve students' communication and problem-solving skills along with their cooperative spirit. In addition, it also helps to deepen students' understanding of this subpart by summarizing as such: "If the criticism is so vague or general that we are not sure exactly what it is that displeases someone, we can ask for the details!"

Finally, in Task 4, students will be able to understand the main idea of Part 3 by filling in the blanks. By playing videos that involve celebrities being criticized, it does not only help students to feel more relax, but also enable them to understand the attitude of the author of the text: "Learn to respond to criticism positively; ignore it when it is inappropriate but learn from it when it is justified."

All in all, all of these four tasks embody the student-centered principle and the learning-by-doing principle.

\subsection{Task design and the design intent in the post-reading phase}

In the post-reading phase, a debate can be carried out. The subject of the debate can be as such: "Which one makes people better, criticism or praise?". Stories and examples should be used to support the students' viewpoints. Students of the same opinion will be requested to form a group, and they will be encouraged 
to use their personal experience or information they have gathered from newspapers or internet to support their viewpoints.

This task can arouse awareness of establishing good relationships with each other either by criticism or by praise. It reflects the theme of the text: "We should have a correct attitude toward criticism."

In a word, these tasks embody the goal-oriented and outcome principle.

\section{Conclusion}

TBLT is a recently developed approach in line with CLT. It focuses on learning by doing rather than the form of language itself. This paper has offered information about designing better tasks upon understanding the theory of TBLT and task as well as the principles of task design. When designing tasks, teacher should pay attention to students' needs, interests, experiences, and abilities. In order to improve students' English language capacity and communicative competence in addition to the teaching effect, teachers should adopt different teaching methods based on specific contexts.

\section{Disclosure statement}

The author declares that there is no conflict of interest.

\section{References}

[1] Richards J, Rodgers T, 1986, Approaches and Methods in Language Teaching, Cambridge University Press, Cambridge.

[2] Wang Q, 2006, A Course in English Language Teaching, High Education Press, Beijing.

[3] Prabhu NS, 1987, Second Language Pedagogy, Oxford University Press, Oxford.

[4] Candling C, Murphy D, (eds) 1987, Language Learning Tasks, Prentice Hall, London.

[5] Nunan D, 1989, Designing Tasks for Communicative Classroom, People's Education Press, Beijing.

[6] Willis J, 1996, A Framework for Task-Based Learning, Longman, Harlow.

[7] Brown HD, 1994, Teaching Principles, Prentice-Hall, New Jersey. 